\title{
Innovator Filgrastim versus Generic Filgrastim in Hematopoietic Stem Cell Transplantation Mobilization
}

\author{
Sadik Husian ${ }^{1}$ Preethi Jeyaraman ${ }^{2}$ \\ Rahul Naithani² \\ 1Department of Pharmacology, Pharmaceutical Sciences and \\ Research University, New Delhi, India \\ ${ }^{2}$ Division of Hematology and Bone Marrow Transplant, Saket, \\ New Delhi, India \\ ${ }^{3}$ Division of Transfusion Medicine, Department of Lab Medicine \\ Transfusion Medicine, Max Super Specialty Hospital, Saket, \\ New Delhi, India
}

\author{
S. K. Gupta ${ }^{1}$ Reeta Rai ${ }^{3}$ Sangeeta Pathak ${ }^{3}$ Nitin Dayal ${ }^{4}$
}

South Asian J Cancer 2021;10:172-174.

\author{
Abstract \\ Rahul Naithani
}

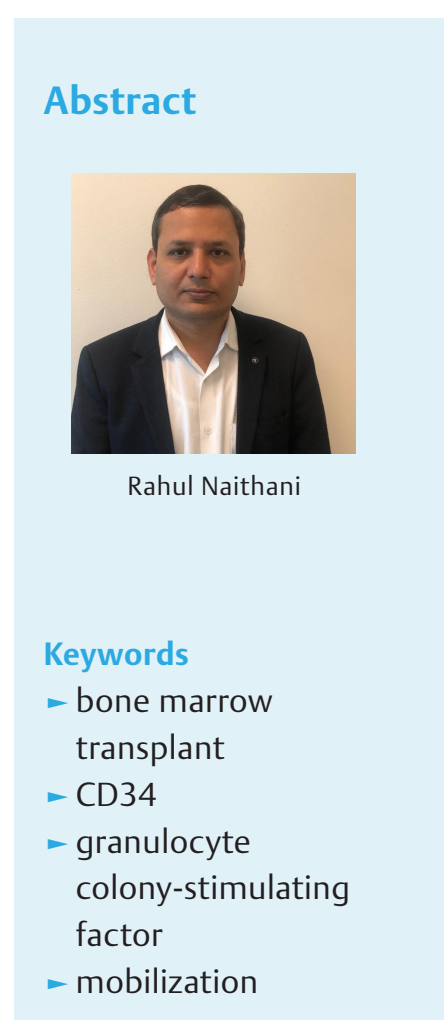

\begin{abstract}
Address for correspondence Rahul Naithani, Division of Hematology and Bone Marrow Transplant, Max Super Speciality Hospital, Saket, Delhi 110017, India (e-mail: dr_rahul6@ hotmail.com).
${ }^{4}$ Department of Lab Medicine, Max Super Specialty Hospital, Saket, New Delhi, India

\begin{abstract}
Methods This is a retrospective study. G-CSF was administered in the dose of $10 \mu \mathrm{g} /$ $\mathrm{kg}$ subcutaneous as a single dose for 4 days. On day 5 , peripheral blood stem cell (PBSC) apheresis was performed using Haemonetics MCS plus or COBE Spectra apheresis machine through a double-lumen central venous catheter. Primary outcome parameters were the total number of $\mathrm{CD} 34+\mathrm{HSCs} / \mathrm{kg}$ of recipient weight mobilized in peripheral blood and the number of days required for neutrophil and platelets engraftment, respectively.

Objective We compared the effectiveness and safety of innovator filgrastim versus generic filgrastim in patients who underwent hematopoietic stem cell transplantation (HSCT).

Results A total of 91 stem cell mobilizations was analyzed. There were 58 normal healthy donors for allogeneic HSCT and 33 patients for autologous HSCT. There was no statistically significant difference among groups in terms of total collected CD34+ cells value $(p=0.609)$. The mean time to neutrophil engraftment was 13.7 days in the innovator group and 13.2 days in the Grafeel group $(p=0.518)$. The mean time to platelet engraftment was 16.2 days in the innovator group and 14.8 days in the generic group $(p=0.435)$. The patient who received generic filgrastim had more febrile episodes during the course of transplantation $(p=0.020)$.

Conclusion Generic filgrastim was found to be comparable to original filgrastim for peripheral blood stem cell mobilization in normal healthy donors for allogeneic HSCT and patients for autologous HSCT.
\end{abstract}

\section{Introduction}

Hematopoietic stem cell transplantation (HSCT) is the treatment modality of choice in various hematological conditions. ${ }^{1}$ Adequate mobilization of stem cells is an essential prerequisite for timely engraftment in HSCT. A consensus published by the American Society for Blood

\section{DOI https://doi.org/10.1055/s-0041-1729446 ISSN 2278-330X}

How to cite this article: Husian S, Jeyaraman P, Gupta K. S, et al. Innovator Filgrastim versus Generic Filgrastim in Hematopoietic Stem Cell Transplantation Mobilization. South Asian J Cancer 2021;10(3):172-174. and Marrow Transplantation recommends collecting a minimum dose of $2 \times 10^{6} \mathrm{CD} 34+$ cells/ $\mathrm{kg}$ to perform autologous stem cell transplantation. ${ }^{2}$ Granulocyte colony-stimulating factor (G-CSF) forms the backbone of the mobilization strategy.

A generic is a biological medicine that is highly similar to another already approved biological medicine (reference or

(c) 2021. Medlntel Services Pvt Ltd.

This is an open access article published by Thieme under the terms of the Creative Commons Attribution-NonDerivative-NonCommercial-License, permitting copying and reproduction so long as the original work is given appropriate credit. Contents may not be used for commercial purposes, or adapted, remixed, transformed or built upon. (https://creativecommons.org/licenses/by-nc-nd/4.0/).

Thieme Medical and Scientific Publishers Private Ltd A-12, Second Floor, Sector -2, NOIDA -201301, India 
innovator medicine). The innovator G-CSF Neupogen (Amgen, Vienna, Austria) was used initially for stem cell mobilization in autologous and healthy donors. Following the patent expiration of the innovator filgrastim product, generic filgrastim products have been approved in the European Union (EU) and have been shown to be comparable with the innovator with respect to quality, safety, and efficacy. In developing countries with lesser regulated markets, data on quality of generics are limited. A recent meta-analysis by Schmitt et al, based on 30 studies with a total of 1,541 autologous transplant patients where generic filgrastim was used for hematopoietic stem cell (HSC) mobilization, found no differences in the number of apheresis days, the number of collected $\mathrm{CD} 34+$ cells/kg recipient weight, or the time to neutrophil and platelet engraftment compared with Neupogen. ${ }^{3}$ Nupur et al analyzed in vitro bioactivity and structural variability between Neupogen and Indian generics (Emgrast, Emcure, India; Lupifil, Lupin, India Colstim, Zydus, India Neukine, Intas Pharmaceuticals, India Grafeel, Dr. Reddy's Laboratory, India) and found them to be comparable. ${ }^{4}$ In our center, we were using generic G-CSF in our other hematology patients but for HSC mobilization, innovator G-CSF was exclusively used. We had to shift to generic G-CSF due to the withdrawal of innovator G-CSF from the Indian market in 2014. In the present article, we compared the in vivo effectiveness and safety of innovator filgrastim versus generic filgrastim in the Indian Scenario.

\section{Methods}

We performed a retrospective analysis of 58 donors and 33 patients who used G-CSF for HSC mobilization. All autologous or allogeneic HSCT patients used innovator G-CSF till October 2014 when innovator G-CSF (Neupogen, Roche) was withdrawn from India. All donors and patients after this time used Indian generic G-CSF (Grafeel, Dr. Reddy's Laboratory, India). G-CSF was administered in the dose of $10 \mu \mathrm{g} / \mathrm{kg}$ subcutaneous as a single dose for 4 days. On day 5 , peripheral blood stem cell (PBSC) apheresis was performed using Haemonetics MCS plus or COBE Spectra apheresis machine through a double-lumen central venous catheter. Stem cell yield of the harvest was determined by CD34 cell enumeration using the ISHAGE protocol. ${ }^{5}$ The goal of apheresis was to collect an average of $2 \times 10^{6} / \mathrm{kg}$ CD34 stem cells. A second harvest was not attempted if dose was $2 \times 10^{6} / \mathrm{kg}$ CD34 stem cells or more due to financial reasons. Patients received G-CSF $5 \mu \mathrm{g} / \mathrm{kg}$ once a day starting on day +6 after the infusion of stem cells until the time of engraftment. ${ }^{6}$ Neutrophil engraftment was defined as the first of 3 consecutive days of the absolute neutrophil count of at least $0.5 \times 10^{9} / \mathrm{L}$, whereas platelet engraftment was defined as the first of 3 consecutive days of platelet count of at least $20 \times 10^{9} / \mathrm{L}$ without transfusion support. Statistical analysis was performed using SPSS, IBM, Chicago, Illinois, USA software, version 20.0. The study was approved by the Institute's Ethics Committee.

Primary outcome parameters were the total number of $\mathrm{CD} 34+\mathrm{HSCs} / \mathrm{kg}$ of recipient weight mobilized in peripheral blood and the number of days required for neutrophil and platelets engraftment, respectively.

\section{Results}

A total of 91 HSC mobilizations was analyzed. There were 58 normal healthy donors for allogeneic HSCT and 33 patients for autologous HSCT. General patient's characteristics are shown in - Table 1. - Table 2 demonstrates the HSCs collected between the two groups. There was no statistically significant difference among groups in terms of total collected CD34+ cells $/ \mathrm{kg}$ recipient weight ( $p=0.609$ ). Nine patients (two in the innovator and seven in the Grafeel group)died before the meaningfulengraftment could take place. These patients were excluded from the analysis. The mean time to neutrophil engraftment in other patients was 13.7 days in the Neupogen group and 13.2 days in the Grafeel group ( $p=0.518)$. The mean time to platelet engraftment was 16.2 days in the innovator group and 14.8 days in the generic group ( $p=0.435)$. The patient who received Grafeel had more febrile episodes during the course of transplantation ( $p=0.020$; - Table 1). However, occurrence of fever is multifactorial event, and the single most important contributing factor is neutrophil count.

\section{Discussion}

Multiple studies have been conducted in the EU comparing Neupogen and generic filgrastim. Sivgin et al have recently demonstrated that there was no statistically significant difference in HSC collection between innovator and generic G-CSF Leucostim, Biocad, Russia for PBSC mobilization in donors of the patients who underwent allogeneic HSCT. ${ }^{7}$

Table 1 Patient characteristics

\begin{tabular}{|l|l|l|l|}
\hline Variables & $\begin{array}{l}\text { Innovator } \\
\text { G-CSF }\end{array}$ & $\begin{array}{l}\text { Generic } \\
\text { G-CSF }\end{array}$ & Total \\
\hline Male & 22 & 35 & 57 \\
\hline Female & 6 & 28 & 34 \\
\hline Diagnosis & & & \\
\hline AML & 3 & 4 & 7 \\
\hline ALL & 5 & 3 & 8 \\
\hline Lymphoma & 1 & 5 & 6 \\
\hline AA & 1 & 6 & 7 \\
\hline Myeloma & 6 & 17 & 24 \\
\hline Thalassemia & 0 & 17 & 17 \\
\hline CML & 3 & 4 & 7 \\
\hline Others & & & 15 \\
\hline Autologous HSCT & 9 & 24 & 33 \\
\hline Allogeneic HSCT & 19 & 39 & 58 \\
\hline Febrile episode $(p=0.020)$ & & & \\
\hline Yes & 20 & 57 & 77 \\
\hline No & 8 & 6 & 14 \\
\hline
\end{tabular}

Abbreviations: ALL,Acute lymphoblastic leukemia; AA,Aplastic anemia; AML, acute myeloid leukemia; CML, chronic myeloid leukemia; G-CSF, granulocyte colony-stimulating factor; HSCT, hematopoietic stem cell transplantation. 
Table 2 Hematopoietic stem cell dose $\left(\times 10^{6} / \mathrm{kg}\right)^{\text {a }}$

\begin{tabular}{|l|l|l|l|l|}
\hline & $<2 \times 10^{6} / \mathrm{kg}$ & $\mathbf{2 - 5} \times 10^{6} / \mathrm{kg}$ & $>5 \times 10^{6} / \mathrm{kg}$ & Total \\
\hline Innovator G-CSF & 1 & 17 & 10 & 28 \\
\hline Generic G-CSF & 7 & 32 & 24 & 63 \\
\hline Total & 8 & 49 & 34 & 91 \\
\hline
\end{tabular}

Abbreviation: G-CSF, granulocyte colony-stimulating factor. ${ }^{\mathrm{a}} \mathrm{p}=0.609$.

Another retrospective single-center study on 98 patients revealed that the median HSC dose collected was 4.7 versus 6 million/kg in generic and innovator arm ( $p=$ not significant). The median time to neutrophil engraftment was similar in both arms; however, platelet engraftment was delayed (20 vs. 18 days; $p=0.01$ ) in the generic arm. ${ }^{8}$ We, like other studies, did not observe such difference.

Another larger retrospective study demonstrated the similarity of innovator and generic product in terms of HSC dose, number of days required for collection, or time to engraftment. ${ }^{9}$

Bassi et al studied the use of generic G-CSF during the course of transplant also. They had a similar protocol as ours, where G-CSF was used from day + 5 onward. Results in terms of $\mathrm{CD} 34+$ cell counts and time to engraftment were similar. They, however, observed the higher incidence of febrile neutropenia. ${ }^{10}$ We also noted higher febrile episodes in the generic arm. Infections are the function of various variables. Like us, the authors of this article also felt that the difference was due to different preventive and prophylactic protocols for infections.

A prospective study compared innovator and generic products during chemomobilization for HSC collection in 108 patients with hematological malignancies. The median duration of the G-CSF administration was 8 days, a median of one apheresis was performed, and similar HSC dose was harvested in both groups. Rates of mobilization failures and adverse event profile were similar between the groups. ${ }^{11}$

A recent review of published studies of 1,541 autologous and 492 donors concludes that there was no difference in innovator and generic G-CSF in efficacy and safety. ${ }^{12}$

\section{Limitations}

We were using generic G-CSF in our other hematology patients but for HSC mobilization, the innovator G-CSF was exclusively used. We had to shift to generic G-CSF largely due to the withdrawal of innovator G-CSF from the Indian market. We are not discussing progression-free survival and other outcomes, as these are not dependent if HSCs were mobilized using innovator or generic and actually depend on multiple clinical variables. The main limitation of our data as with the previous several studies is the retrospective nature of the analysis.

\section{Conclusion}

Generic filgrastim was found comparable to original filgrastim for PBSC mobilization in normal healthy donors for allogeneic HSCT and patients for autologous HSCT.

\section{Financial Support and Sponsorship}

None

\section{Conflicts of Interest}

There are no conflicts of interest.

\section{References}

1 Majhail NS, Farnia SH, Carpenter PA, et al. Indications for autologous and allogeneic hematopoietic cell transplantation: guidelines from the American Society for Blood and Marrow Transplantation. Biol Blood Marrow Transplant 2015;21(11):1863-1869

2 Giralt S, Costa L, Schriber J, et al. Optimizing autologous stem cell mobilization strategies to improve patient outcomes: consensus guidelines and recommendations. Biol Blood Marrow Transplant 2014;20(3):295-308

3 Schmitt M, Hoffmann JM, Lorenz K, Publicover A, Schmitt A, Nagler A. Mobilization of autologous and allogeneic peripheral blood stem cells for transplantation in haematological malignancies using biosimilar G-CSF. Vox Sang 2016;111(2):178-186

4 Nupur N, Singh SK, Narula G, Rathore AS. Assessing analytical comparability of biosimilars: GCSF as a case study.J Chromatogr B Analyt Technol Biomed Life Sci 2016;1032:165-171

5 Naithani R, Dayal N, Dixit G. Single versus dual platform analysis for hematopoietic stem cell enumeration using ISHAGE protocol. Indian J Hematol Blood Transfus 2017;33(3):370-374

6 Naithani R, Dayal N, Pathak S, Rai R. Hematopoietic stem cell transplantation using non-cryopreserved peripheral blood stem cells graft is effective in multiple myeloma and lymphoma. Bone Marrow Transplant 2018;53(9):1198-1200

7 Sivgin S, Karakus E, Keklik M, et al. Evaluation of the efficacy and safety of original filgrastim (Neupogen), biosimilar filgrastim (Leucostim) and Lenograstim (Granocyte) in CD34(+) peripheral hematopoietic stem cell mobilization procedures for allogeneic hematopoietic stem cell transplant donors. Transfus Apheresis Sci 2016;54(3):410-415

8 Pham T, Patil S, Fleming S, et al. Comparison of biosimilar filgrastim with originator filgrastim for peripheral blood stem cell mobilization and engraftment in patients with multiple myeloma undergoing autologous stem cell transplantation. Transfusion 2015;55(11):2709-2713

9 Publicover A, Richardson DS, Davies A, et al. Use of a biosimilar granulocyte colony-stimulating factor for peripheral blood stem cell mobilization: an analysis of mobilization and engraftment. Br J Haematol 2013;162(1):107-111

10 Bassi S, Stroppa EM, Moroni CF, et al. Safety and efficacy of granulocyte colony-stimulating factor biosimilars in engraftment after autologous stem cell transplantation for haematological malignancies: a 4-year, single institute experience with different conditioning regimens. Blood Transfus 2015;13(3):478-483

11 Manko J, Walter-Croneck A, Jawniak D, et al. A clinical comparison of the efficacy and safety of biosimilar G-CSF and originator G-CSF in haematopoietic stem cell mobilization. Pharmacol Rep 2014;66(2):239-242

12 Pahnke S, Egeland T, Halter J, et al; Working Group Medical of the World Marrow Donor Association. Current use of biosimilar G-CSF for haematopoietic stem cell mobilisation. Bone Marrow Transplant 2019;54(6):858-866 